\title{
Neurology in the United Kingdom. I: historical development
}

\author{
R Langton Hewer, V A Wood
}

\begin{abstract}
International comparisons suggest that British neurological services are underdeveloped. Historical factors which have contributed to the current state of neurological services in the United Kingdom are described. Key issues include the dominance of London and the concept of specialised hospitals in the early history of neurology; the subsequent recognition of the needs of other parts of the United Kingdom, of district general hospitals, and of patients with chronic neurological disabilities not necessarily included within the traditional bounds of neurology; and the relationship between neurology and general medicine. The paper concludes with some suggestions as to how neurology services might develop in the future.
\end{abstract}

"The United Kingdom must have one of the worst neurology services in the Western World." The speaker was a colleague from North America and he was commenting on the small number of clinical neurologists in the United Kingdom (UK) compared with the rest of the Western World. How could such a comment have been made, 150 years after neurology was officially recognised as a special branch of medicine, more than 125 years since the opening of the National Hospital in London, ${ }^{1}$ and over 100 years since the formation of the Neurological Society of London and the inception of the journal Brain-A Journal of Neurology?

THE HISTORY OF NEUROLOGY

Neurology as we know it today is founded upon the brilliance, skill and persistence of our eminent predecessors. Biographical sketches of one hundred and forty six "Founders of neurology" are presented in the book of this title by Haymaker and Schiller. ${ }^{2}$ Experimental approaches to the study of the nervous system were introduced by Thomas Willis (1621-75), the Oxford neuroanatomist. Willis' work led to the first advances in knowledge of the nervous system and, in his book "De Cerebri anatome" published in 1664, he was the first to use the term "neurology", meaning the knowledge of the cranial, spinal and autonomic nerves. ${ }^{2}$

In the early nineteenth century there were many significant contributions to neurology from the UK. In 1817 James Parkinson (17551828) first recognised the disease since named after him, in his "Essay on the Shaking Palsy". 3
Sir Charles Bell (1774-1842), Professor of Surgery in Edinburgh, made a significant contribution to the knowledge of the nervous system. His famous book, "The Nervous System of the Human Body", was published in 1830 and was translated two years later into German by Romberg who was, shortly afterwards, appointed to lecture on neurology in Berlin. $^{1}$

In the later part of the nineteenth century, distinguished workers abroad and in the UK (such as Hitzig, Fritsch, Ferrier) defined the existence of areas in the cortex of the forebrain from which movements could be elicited by adequate stimulation. Later it was found that messages from peripheral sense organs reach specific cortex areas. "Clinical observations also demonstrated that in man the cortex is essential for purposive movement, conscious sensation, vision and hearing as well as for his mental and intellectual activity."

It was Jean Martin Charcot (1825-93), under whom the French school of neurology attained eminence, who first established clinical neurology as an autonomous discipline and who, in 1882, was appointed the first professor of diseases of the nervous system. Among his many achievements he advanced the discipline of nosology and established disseminated sclerosis as an entity. His name is linked with peroneal muscular atrophy ${ }^{2}$ and many other clinical syndromes.

NEUROLOGY IN LONDON

The National Hospital for the Relief and Cure of the Paralysed and Epileptic, as it was originally called, opened in June 1860 in an old and ill-adapted house in Queen Square, London, with accomodation for eight patients. Its foundation was due to the untiring efforts of Miss Johanna Chandler, who for 15 years devoted her life to its welfare and to the comfort of its patients. ${ }^{1}$

In the early years of the National Hospital little was known about the central nervous system and few of the more common diseases were clearly recognised. ${ }^{4}$ Its foundation, however, attracted the foremost neurologists of the day, and it soon became a focus for study and a centre which rivalled the Salpetriere. ${ }^{5}$

For some years London remained the only place in the UK where people suffering from diseases and disorders of the nervous system could obtain specialist help. When Purdon Martin joined the National in 1920 little neurology in this country was being practised outside London. $^{6}$ 
EXPANSION OF THE SPECIALTY

Neurology gradually expanded to the provinces, initially by former Queen Square house physicians establishing chiefly neurological practices. ${ }^{6}$ In 1954 the Royal College of Physicians (RCP) Committee on Neurology reported that 50-60 neurologists were practising in England and Wales, with $50 \%$ of these working in London. ${ }^{7}$ An enquiry among consultant psychiatrists showed that "while the need for neurological consultants was adequately covered in London, it was not adequately covered in the provinces".?

By the late 1950s the view was commonly held that there was no substitute for the special hospital, in the context of a place of reference for the difficult problem and as a training and research centre. ${ }^{8-10}$ Some were of the opinion that many of its functions could not be efficiently discharged by general physicians or neurologists working in a general teaching hospital. ${ }^{10}$ Others, however, recognised that some neurological disorders were not seen at a special hospital and that the general hospital offered opportunities which were complementary to those of the specialist institutions. ${ }^{89}$

The 1954 RCP Neurology Committee's report suggested a considerable increase in the total number of neurologists and a more even distribution throughout the country, in accordance with the distribution of the population. ${ }^{7}$ Around the same period, during the 1940 s and 1950 s, one of the fundamental basic concepts of the National Health Service-the District General Hospital-emerged. The idea of providing, under one roof, inpatient and outpatient facilities for the population of a District was accepted in the hospital plan of 1962, which suggested hospitals of $600-800$ beds serving a population of $100000-150000 .^{11}$ General hospitals have been viewed as having doctors allied to all the main specialties within medicine. ${ }^{12}$

In 1959 the ratio of population per neurologist was reported to be 400000 persons across the metropolitan area and 1.2 million per neurologist in the provincial regions. ${ }^{10}$ The variation in regional ratios was wide, for example, although three neurosurgeons were practising in Liverpool (Mersey Region, population $2.1 \mathrm{~m}$ ) there were no neurologists; in Newcastle (Northern Region, population $2.9 \mathrm{~m}$ ) there were four consultant neurosurgeons and two consultant neurologists. ${ }^{10}$ During the 1960 s and 1970 s there was an increase in the number of provincial neurological centres. ${ }^{13-16}$

The 1970 RCP Report on Neurological Manpower suggested $2 \cdot 2$ consultant sessions per 100000 population. ${ }^{17}$ These figures were derived from the Platt Committee Report on Medical Staffing Structure (1966). ${ }^{18}$ This figure was accepted by the London Health Planning Consortium in their Report of a Study Group on Neurology and Neurosurgery (1980). ${ }^{19}$

By the mid 1980s, neurology as a specialty had grown, but remained small. One hundred and ninety consultant neurologists were in post in the UK in June 1987 and the overall ratio of population to whole-time-equivalent (WTE) neurologist was 373000 persons to one. ${ }^{20}$ One hundred and five consultant neurologists $(55 \%)$ worked in the Thames Regions and/or the special hospitals in London, and the ratio of population to WTE neurologists there was 250000 persons to one. ${ }^{20}$

In 1987 there was a wide variation in the distribution of consultant neurologists in different parts of the country. ${ }^{20}$ Only $22 \%$ of the 200 Health Districts in England and Wales had the equivalent of one full time neurologist (11 weekly sessions) or more- $43 \%$ had less than three consultant neurological sessions per week. The current organisation of neurological services is discussed in more detail in our second article. ${ }^{21}$

In 1988 the Association of British Neurologists adopted the policy that each Health District should have available to it the services of one consultant neurologist on the basis of at least one full time specialist for each 200000 persons. ${ }^{22}$ In his analysis of his own workload, Stevens considered that this must be regarded as an achievable interim objective because the real need was probably for an even smaller population per consultant. ${ }^{23}$

It is interesting that in 1987 in the United States there were about 32400 people per neurologist and in Canada the ratio was about 63100 people per practising neurologist. Ratios are similar in most Western European countries.

The scope of neurological practice and care in England, Canada and the United States was analysed by Menken et al. ${ }^{24}$ They asserted that in the UK almost no emergencies were admitted to a neurologist's care and the British health system assumes that general physicians have sufficient education, training and experience to manage most of the common disorders that affect the nervous system.

The problem of the small number of neurologists in Britain is compounded by the fact that the specialty of rehabilitation medicine is under-developed. Most, if not all Western countries, have a substantial specialty of rehabilitation whose members are involved in the management of disability due to neurological disease. This applies particularly to North America, New Zealand and Australia. In the UK there is only a handful of consultants practising full time in rehabilitation medicine, which was first recognised as a separate specialty by the Department of Health as recently as 1991. A report of the Royal College of Physicians ${ }^{22}$ suggested that in each Health District there should be a total of 10 consultant sessions in rehabilitation medicine-possibly divided between three consultants. The report expressed the view that neurologists, among others, could "take up" some of these sessions.

In the late 1950s Lord Brain highlighted changes in the neurological scene which had been brought about by new diseases and the increased incidence of old diseases, together with changes in the age distribution of the population. ${ }^{8} \mathrm{He}$ argued that the scope of neurology was too wide for general physicians to undertake all neurological work which presented in a general hospital. 
The RCP Neurology Committee's report of 1954 argued that the need for more neurologists could be demonstrated by the steady increase in the number of cases attending the new neurology centres which had been set up over the past five years, as well as the turnover of inpatients. ${ }^{7}$ Brinton also argued that "the establishing of a neurological service quickly demonstrates the need of the local population". 10

As Stevens recognised, the starting point in establishing need is to estimate how much neurological disease is present in the community. ${ }^{23} \mathrm{~A}$ major survey of the epidemiology of neurological disease was undertaken by Brewis et $a .^{25}$ They surveyed the population of Carlisle and found that the total prevalence, adjusted for the British population, was $1100 /$ 100000 , or one per cent (these figures did not include congenital or paediatric diseases). A Health District (with a population of a quarter of a million persons) would contain at least 2500 persons with significant neurological disease. More recently, acute neurological disease has accounted for about $20 \%$ of admissions to medical wards. ${ }^{26}$

The scope of neurology was recognised by the World Health Organisation to be so large that it warranted a special volume of the International Classification of diseases-a copy of which was published for trial purposes in $1987 .{ }^{27}$

A recent review of the epidemiology of neurological diseases ${ }^{28}$ suggests that the annual incidence of seven important causes of neurological disability exceeds 500 per 100000 . The overall prevalance for this group is about 2500 per 100000 , with 1400 being disabled (including about 500 epileptics on treatment).

\section{NEUROLOGICAL DISABILITY}

In 1959 Brinton highlighted two "new" burdens which he felt should be shouldered by neurologists: the medical care of epileptics and the supervision of the neurological chronic sick. ${ }^{10} \mathrm{He}$ reported that no serious attempt to implement the recommendations of the Cohen report ${ }^{29}$ (on medical care of epileptics) had been made, and the problem of the chronic sick had not been officially tackled by the Ministry. ${ }^{10}$ Finding a hospital bed for an incurable patient was difficult and, even when one was acquired, the patient was unlikely to receive any specialist treatment and rarely any physiotherapy or occupational therapy. ${ }^{10}$ The RCP Neurology Committee's report in 1965 also reported that "the chronic neurological case $\operatorname{seem}(\mathrm{s})$ to be neglected through lack of facilities". ${ }^{30}$

Miller, in the late 1960s expressed the view that historical circumstance had deprived the clinical neurologist of responsibility for either the long-term sick or care of the patient with chronic neurological disease. ${ }^{31}$ However, he strongly contended that "there can be no doubt that this responsibility belongs to him, and that every unit should undertake the supervision of patients in both groups". ${ }^{31}$

In the 1980s physical disability was the subject of considerable debate. Two reports from the Royal College of Physicians of
London, "Physical Disability in 1986 and Beyond", "32 and "The Young Disabled Adult", ${ }^{33}$ drew attention to the problems posed by physical disability. The former suggested that the management of disability is the responsibility of all clinicians, and that the provision of appropriate generic services should help them to deal with their disabled patients. Both reports identified three particular areas of major concern to neurologists: 1) disabled people between the ages of $16-64 ; 2)$ patients recovering from a head injury; 3 ) the disabled school leaver, most of whom suffer from neurological disease.

\section{RELATIONSHIP OF NEUROLOGY TO GENERAL MEDICINE}

The subject of neurology was recognised by many in the 1940s to be so large that "to keep abreast with its theory and practice in all their aspects is in itself sufficient to occupy the whole professional time and energy of anyone who wishes to be a master of the subject". ${ }^{34}$ The RCPs Committee on Neurology, however, stated that neurology must not allow itself to be separated from general medicine. ${ }^{34}$ They recommended that all neurologists should be of consultant status and should hold a higher qualification in general medicine (MRCP or equivalent) before starting 48 months wholetime study of clinical neurology.

In anticipation of the NHS, the 1945 report suggested that "the services of a trained neurologist shall be available for any member of the public who needs them irrespective of his economic position or place of residence". ${ }^{34}$ The total number of neurologists in the UK at that time was reported to be approximately 60 . It was evident that many acute neurological cases would not have access to a neurologist. The committee suggested that "the care of such cases will properly fall to the general physician of the appropriate area or hospital who combines an interest and training in neurology with his general medicine. Such clinicians, it is hoped, would establish a close liaison with the neurological centre in their region". ${ }^{34}$

In 1954 the RCP Neurology Committee reported its regret that the position of neurology was worse (under the NHS) than it had been in $1945 .{ }^{35}$ It suggested that some in influential positions held the view that the practice of teaching and general medicine might be impoverished by the appointment of more neurologists and that neurology in the provinces should be carried out by general physicians. The Neurology Committee argued that this view was short-sighted and contrary to the best interests of the Health Service and that a fully trained neurologist could make a contribution both in diagnosis and treatment in most neurological cases. They did not suggest that all cases of neurological illness be segregated under the direct care of a neurologist, but recommended that an expert neurological opinion should be available whenever it was needed.

In 1959 Brinton suggested that, to cover the serious shortage of neurologists in England and Wales, general physicians with an interest and 
some special training in neurology were unquestionably useful in a few parts of the periphery of the country, although they should maintain a close contact with the nearest neurological centre. ${ }^{10}$

In 1965 the RCP Committee on Neurology suggested that neurology is best practised in a general hospital. ${ }^{30}$ They reported that the neurological sick were being nursed in general medical beds, without the benefit of the facility of an efficient local neurological unit but that some sub-acute disorders might be referred to a neurological unit elsewhere, although chronic neurological cases seemed to be neglected through lack of facilities. However, the report stated that neurology cannot be practised efficiently by a general physician, and that the concept of a physician with an interest in neurology was "outmoded".

Later in the 1960s Miller continued the argument, contending that there was a place for the general physician with a special neurological interest, and suggesting that advances in neurology should be achieved without dissociating the specialty from general medicine. ${ }^{31}$ $\mathrm{He}$ pointed out that remarkable cardiological advances had been achieved without dissociating the specialty from general medicine. ${ }^{31}$ Indeed, it is clear that many specialties, including endocrinology, chest disease and gastroenterology, can be successfully combined with general medicine.

However, the Royal College of Physicians' Report of $1986^{36}$ suggested that it would be a retrograde step to appoint general physicians with a special interest in neurology in District Hospitals. It was felt that general physicians with an interest would not acquire the necessary expertise to deal competently with rare conditions and resources may be wasted by the use of unnecessary investigations. The 1986 report also suggested that physicians practising specialist neurology would need to have access to beds on a neurological unit and this would not be practicable for general physicians with an interest. The Committee felt that the only solution was expansion of the neurological consultant establishment.

In the late 1970s the Royal College of Physicians were reported to be aware of the "mounting anxiety that ... general medicine was being eroded by the development of relative specialties based on technology, the increasing clinical commitment of haematologists, the broadening interests of radiotherapists and anaesthetists, and the growth of specialties such as general practice, accident and emergency, and medical care of the elderly". ${ }^{37}$

As in the $1950 \mathrm{~s}$, there seems to be an indication that in the $1970 \mathrm{~s}$ and $1980 \mathrm{~s}$ neurology and general medicine were becoming increasingly isolated from one another. On the one hand neurologists insisted that it was necessary to train "pure" neurologists and expand the small consultant complement. On the other hand, physicians felt that general medicine should not be eroded by the creation and expansion of different specialties. The debate has now raged for more than 45 years and, at present, seems no nearer being resolved in the 1990s than it was in the 1940s.

\section{Neurological Education}

The scope of neurological disease is large, but the complement of consultant neurologists is small. The majority of patients with acute neurological problems are currently being managed in district general hospitals by general physicians. How well trained are they for this task? Davidson and $\mathrm{King}^{37}$ examined the specialist interest of 1031 general physicians in England and Wales and Northern Ireland. They found that few (9) had an expressed interest in neurology, and only four had neurology in their contracts.

The cornerstone of teaching neurology to undergraduates is seen to be clinical attachment to a neurological department. ${ }^{38}$ Wilkinson's survey, in $1990,{ }^{38}$ indicated that this was available to every student in 20 of the 28 medical schools in the UK and was full time in just 11. The most common arrangements were either full time for four weeks or part time for six weeks. ${ }^{39}$ Only six schools had specific arrangements to give students any training in neurological/neurosurgical emergencies. ${ }^{38}$

Wilkinson's original survey ${ }^{38}$ also indicated that "the assessment of students in neurology/ neurosurgery is crucial in only one school". "In 11 . . . schools, no specific assessment whatsoever is made of students' knowledge, clinical skills and attitudes in neurology and neurosurgery."

From Wilkinson's surveys it seems clear that many students are qualifying in medicine without having received any form of systematic training or assessment in neurology.

All trainee physicians will be involved with the management of some neurological patients, but not all will have been attached to a specialist neurology firm. It is possible for a physician to be appointed to a consultant post without ever having had any specific neurology training. Precisely how often this happens is not known, but experience indicates that the situation is not uncommon.

FUTURE ORGANISATION OF NEUROLOGY SERVICES The considerable size and scope of the problems posed by neurological disease has been discussed elsewhere in this paper. Two of the most important elements are the small number of consultant neurologists, and the lack of training of general physicians in neurology. This results in poor availability within Health Districts of expert neurological advice for emergencies, inpatients and outpatients. Other results include long outpatient waiting lists for a neurological opinion and poorly organised services for the neurologically disabled.

Clearly, the general requirement is to produce the best possible service at reasonable cost. It will be necessary to develop minimum standards of care for the common neurological diseases and much discussion of these is currently occurring. ${ }^{40}$ Agreed standards for purchasers in the reorganised Health Service are required.

The Association of British Neurologists (ABN) has recently issued a Policy document, ${ }^{22}$ which it suggests should be used as a basis for 
future planning. The essential elements are as follows:

1 " Each Health District should have available to it the services of a consultant neurologist on the basis of at least one full time specialist . . for each 200000 of the population."

2 "Neurological services should be available locally so that the patient and his family do not need to travel further than is essential."

3 "Difficult problems will need to be dealt with in the Neurological Centre."

The more detailed recommendations of the ABN for District services include the following:

1 "The majority of neurological emergencies in most Health Districts will continue, for the foreseeable future, to be admitted under the care of general physicians...(However) it should be possible, easily and promptly, to obtain a specialist neurological opinion, ideally on site, for a neurological emergency in the main District General Hospital."

2 "A neurological opinion should easily be obtainable in the main District General Hospital of each Health District for both inpatients and outpatients."

3 "There should be a service for the many patients with neurological disability in each Health District. Sufficient neurology sessions should be provided so that this objective can be met."

It is clear that general physicians will continue to be involved indefinitely with the management of patients with neurological disorders. For this reason, it is suggested that all registrars and senior registrars should have some specific training in neurology. It is also suggested that some general physicians should be encouraged to develop a particular interest and expertise in neurology.

Other ways of linking neurology and general medicine should be considered, for instance, the appointment of a general physician with a particular training and interest in cerebrovascular disease. ${ }^{41}{ }^{42}$ The option of dual accreditation of neurologists in neurology and general medicine should be considered-so that neurologists could take their share of general medical "take". Other developments are obviously possible.

Medical services in London are in need of review ${ }^{43}$ and the King's Fund has set up a Working Group to undertake this task. Clinical neurology will obviously feature in such a review. As elsewhere in the country, any recommendations will need to balance the requirements for locally based services as discussed above, with the need to maintain the research and educational activities which occur in the various undergraduate and postgraduate teaching hospitals-most of which are situated in the middle of London.

The role of the National Hospitals for Nervous Diseases (in Maida Vale and Queen Square) has changed over the last 40 years as a result of the establishment of Regional centres and District services. However, the hospitals have continued to provide a valuable secondary and tertiary referral service for much of the United Kingdom. The National Hospitals also provide a unique teaching service for neurologists who will in the future work elsewhere in the United Kingdom and abroad. In addition, the National Hospitals, together with the Institute of Neurology, are a major focus for neurological research.

\section{Conclusions}

How should we answer our North American colleague who expressed such concern about neurological services in the United Kingdom? Regretfully, we have to concede that there is an element of truth in what he says, although his assertion is clearly overstated. At the same time, it will need to be pointed out that there has been virtually no comparative evaluation of the quality of neurological services in various parts of the world, including Europe. No internationally agreed yardsticks exist.

To achieve the objective of providing an effective neurological service for all UK residents, it will be necessary to develop and agree standards of provision as a basis for assessing the adequacy of services. These standards, once developed, can be used by purchasers of health care. The current reorganisation within the National Health Service presents a window of opportunity. There is a need for more neurologists and for improved training for physicians. It is important to ensure that we collaborate in what is a cause for concern now, and is also a challenging task for the future.

We are grateful for the considerable help we received from $\mathrm{Mr}$ Ben Toth, Librarian, in collecting together the references for this article.

1 Holmes G. The National Hospital, Queen Square. London: $\mathrm{E}$ and $\mathrm{S}$ Livingstone, 1954

2 Haymaker W, Schiller F. The founders of neurology, 2nd ed. Illinois: Charles C Thomas, 1970.

3 Parkinson J. An essay on the shaking palsy. London: 1817.

Milnes JN. History and trends in modern neurology. Brit Clin Pract 1960;14:603-6.

5 Schurr PH. Outline of the history of the Section of Neurology of the Royal Society of Medicine. J Roy Soc Med 1985;78:146-8.

6 Purdon Martin J. British neurology in the last fifty years: some personal experiences. Proc Roy Soc Med 1971; 64:1055-9.

7 Royal College of Physicians of London. Interim Report of the Committee on Neurology. London: RCP, 1954

8 Brain R. Neurology: past, present and future. BMJ 1958; 15:355-60.

9 Miller H. Neurology in the general hospital. BMJ 1958 1:477-80.

10 Brinton $\mathrm{D}$. The development of neurological services under the ministry of health (President's Address). Proc Roy Soc Med 1959;53:261-3.

11 Ferrer HP, ed. The Health Services-administration, research and management London: Butterworths, 1972.

12 Green S. The Hospital:an organisational analysis. London: Blackie, 1974.

13 Newcastle General Hospital. Neurological centre and casualty department. The Hospital 1963;:159-67.

14 Kimber PM. The Wessex Neurological Centre. Radiography 1966;XXXII(378):117-21.

15 Brice JG. The New Wessex Neurological Centre at Southampton. Nursing Times 1965;9:484-6.

16 Harding H. Middlesbrough General Hospital Neurology Unit. Nursing Mirror 1973;27:66.

17 Royal College of Physicians of London. Report on neurological manpower. London: RCP, 1970.

18 Ministry of Health. Department of Health for Scotland Report of the Joint Working Party on the medical staffing structure in the hospital service (Platt Report). London HMSO, 1961.

19 London Health Planning Consortium. Report of a Study Group on neurology and neurosurgery, February 1980.

20 Association of British Neurologists. A report on neurology Wood VA). Number and distribution of consultants in adult 
neurology; Number and distribution of CT head scanners. Bristol: Department of Neurology, Frenchay Hospital: 1990.

21 Langton Hewer R, Wood VA. Neurology in the United Kingdom. II: a study of current neurological services fo adults. J Neurol Neurosurg Psychiatry 1992;55:Suppl 8-14.

22 Association of British Neurologists. A policy statement on the number and distribution of consultants in adult neurology, 1990.

23 Stevens DL. Neurology in Gloucestershire: the clinical workload of an English neurologist. J Neurol Neurosurg workload of an English neurol
Psychiatry 1989;52:439-46.

24 Menken M, Hopkins A, Murray TJ, Vates TS. The scope of neurologic practice and care in England, Canada and of neurologic practice and care in England, Canada and
the United States. Is there a better way? Arch Neurol 1989;46:210-13.

25 Brewis M, Poskanzer DC, Rolland C, Miller $\mathrm{H}$ Neurological disease in an English city. ACTA Neurol Scand 1966;42(Suppl 42).

26 Morrow JI, Patterson VH. The neurological practice of a District General Hospital $J$ Neurol Neurosurg Psychiatry 1987;50:1397-401.

27 World Health Organisation. Application of the International Classification of Diseases to Neurology ICD-NA (Published for trial purposes). Geneva: WHO, 1987.

28 Wade DT, Langton Hewer R. Epidemiology of some neurological diseases with special reference to workload on the NHS. Int Rehabil Med 1987;8:129-37.

29 Central Health Services Council. Report of the Subcommittee of the Medical Care of Epileptics (Cohen Report). London: of the Medical Care of Epileptics (Cohen Report). London

30 Roy Coll Phys London. Committee on Neurology. The neurology services in Great Britain London: 1965.
31 Miller $\mathrm{H}$. The organisation of neurological services and neurological training. Proc Roy Soc Med 1968;61: 1004-10.

32 Roy Coll Phys London. A report on Physical Disability in 1986 and beyond. A report of the Royal College of Physicians London: 1986.

33 Roy Coll Phys London. The Young Disabled Adult. A Report on the Use of Residential Homes and Hospital Units for the age group 16-64. London: 1986.

34 Roy Coll Phys London. Report of the Committee on Neurology. London; July 1945.

35 Roy Coll Phys London. Committee on Neurology. Interim Report, London, 1954.

36 Roy Coll Phys London. Neurological facilities in the United Kingdom Prepared by the College Committee on Kingdom Prepared by the Colle
Neurology London, November 1986.

37 Davidson C, King RC. General medicine in the 'eighties. BMJ 1986;293:547-50.

38 Wilkinson I, Rogers J, Wakeford R. Neurology teaching in UK medical schools. Medical Teacher 1979;2(1):87-92.

39 Wilkinson IMS. A survey of undergraduate teaching of clinical neurology in the United Kingdom 1990. J Neuro Neurosurg Psychiatry 1991:54:226-8.

40 Report of a Working Group Research Unit, Royal College of Physicians: Standards of care for patients with neurological disease A consensus $J$ Roy Coll Phys London 1990; 24(2):90-7.

41 Royal College of Physicians. Stroke: towards better management. London: Royal College of Physicians, 1989.

42 King's Fund Consensus Conference. Treatment of Stroke. ing's Fund Consensus

43 Maxwell R. Closing beds in NHS hospitals (Letter). The Times, 18 May 1990. 